\title{
H2 sensing performance of optical fiber coated with nano-platelet WO3 film
}

\begin{abstract}
For the first time, we have integrated nano-platelet $\mathrm{Pd} / \mathrm{WO} 3$ films, which are formed using an acid etching method, with optical fibers to develop a hydrogen gas (H2) sensors. The tungsten films were firstly RF sputtered on top of optical fiber tips, and subsequently etched in $1.5 \mathrm{M}$ nitric acid to produce tungstite films. After annealing at 300 and $480{ }^{\circ} \mathrm{C}$, these films were coated with approximately $25 \AA$ thick Pd layers. The films were characterized using SEM, GADDS, EDX, and both Raman and UVï visï NIR spectroscopy. H2 testing measurements were conducted when the sensors were interacting with $0.061 \% \mathrm{H} 2$ in synthetic air at an optimum temperature of $100{ }^{\circ} \mathrm{C}$. It was found that the highly crystalline nano-platelet $\mathrm{Pd} / \mathrm{WO} 3$ film based optical fiber $\mathrm{H} 2$ sensors show large reflectance responses in the NIR wavelength of $6 \%$ and $12 \%$ in the presence of $0.06 \%$ and $1 \% \mathrm{H} 2$, respectively.
\end{abstract}

Keyword: Optical fiber sensor; Tungsten trioxide; Nanostructure; H2 